\title{
Extração de madeira e organização social no PDS Virola-Jatobá, Anapu, Pará: Percepções e discursos contrastantes em um assentamento ambientalmente diferenciado
}

\author{
Timber extraction and social organization in the Virola- \\ Jatobá Sustainable Development Project, Anapu, Pará: \\ Contrasting perceptions and discourses within an \\ environmentally-sound land reform settlement \\ Helder do Nascimento Assunção ${ }^{a}$ \\ Roberto Porro ${ }^{b}$ \\ a Mestre em Ciências Ambientais, Universidade Federal do Pará, Belém, PA, Brasil. \\ End. Eletrônico: helnascimento@yahoo.com.br \\ ${ }^{b}$ Doutor em Antropologia Cultural, pesquisador da Embrapa Amazônia Oriental, \\ Belém, PA, Brasil. \\ End. Eletrônico: roberto.porro@embrapa.br
}

doi:10.18472/SustDeb.v9n3.2018.18587

\section{RESUMO}

Projeto de Desenvolvimento Sustentável (PDS) é modalidade de assentamento que visa conciliar reforma agrária e conservação ambiental. Desde a criação do PDS Virola-Jatobá (Anapu, PA), famílias enfrentam dificuldades para consolidar seu assentamento. A extração de madeira conduzida entre 2008 e 2012 por meio de parceria da comunidade com empresa ampliou perspectivas para meios de vida locais. Todavia, problemas na atividade acentuaram processos de ruptura associativa. Neste artigo foi analisada a percepção dos assentados quanto à extração madeireira e benefícios derivados da atividade, e se essa percepção se associou a características das famílias. Para tanto, foram comparados discursos de assentados selecionados conforme acessibilidade do lote, momento de chegada e participação em associações internas. A variável associativa melhor distinguiu percepções quanto à inserção da extração de madeira nas estratégias produtivas locais. $O$ alcance das metas socioambientais previstas nos PDS condiciona-se a ações coletivas harmônicas que pactuem uma agenda consolidada em prol do grupo como um todo.

Palavras-chave: Análise de discurso; Associativismo; Manejo florestal comunitário; Projeto de assentamento. 


\begin{abstract}
$x$ Sustainable Development Project (PDS) is a land tenure modality aiming to reconcile agrarian reform and environmental conservation. Since the creation of Virola-Jatobá's PDS (Anapu, PA), families struggle to consolidate their settlement. Timber extraction conducted between 2008 and 2012 through community partnership with a logging company has broadened local livelihoods' perspectives. However, problems in activity implementation heightened associative disruption. In this article we analyzed settlers' perception regarding logging through forest management and benefits derived from logging as well as whether this perception was linked to household features. Discourses of selected settlers were compared according to lot accessibility, arrival time and participation in internal associations. The associative variable better distinguished perceptions regarding insertion of logging in local productive strategies. The achievement of socio-environmental goals foreseen in the PDS is thus conditioned to collective harmonic actions seeking compromises and a consolidated agenda for the benefit of the entire group.
\end{abstract}

Keywords: Discourse analysis; Social organization; Community forest management; Land reform settlement.

\title{
1 INTRODUÇÃO
}

A Amazônia detém um gigantesco potencial de produção de madeira tropical, bem como de biodiversidade animal e vegetal (MINISTÉRIO DO MEIO AMBIENTE, 2016). A região é alvo de amplo debate acerca de seus problemas ambientais, notadamente os relacionados à substituição da cobertura florestal, pois, mesmo com a brusca redução nas taxas de desmatamento verificada nos últimos 11 anos, passando de uma taxa anual de $19.014 \mathrm{~km}^{2}$ em 2005 para $7.893 \mathrm{~km}^{2}$ em 2016 (INSTITUTO NACIONAL DE PESQUISAS ESPACIAIS, 2017), a grandeza natural da região não esconde a fragilidade do ecossistema local.

A floresta vive a partir de seu próprio material orgânico, e seu delicado equilíbrio é extremamente sensível a quaisquer interferências (SALATI; VOSE, 1984). Os danos causados pela ação antrópica a esse ambiente são muitas vezes irreversíveis (MMA, 2016). Desse quadro resulta que na atualidade o desmatamento tende a penalizar tanto a obtenção de serviços ambientais ${ }^{1}$ da floresta (água, ar, clima, biodiversidade, etc.) como a manutenção da sociodiversidade ${ }^{2}$ existente na região. Ademais, grande parte dos usos da terra que se sucedem à floresta são insustentáveis e de baixo aproveitamento (FEARNSIDE, 2006).

O avanço da ocupação da Amazônia nas últimas décadas associa-se a um contexto perverso, na medida em que em seu âmbito se geram tensões sociais e a predação dos recursos naturais. Os agricultores familiares passam também a contribuir para a redução da cobertura florestal da Amazônia, pois, como afirmam Brandão Júnior e Souza Júnior (2006), apesar da grande importância dos assentamentos rurais para a distribuição de terras, as atividades desenvolvidas pelos assentados, como agricultura, pecuária e extração de madeira, têm grande potencial na geração de desmatamento e degradação florestal na região.

Uma das ações adotadas visando reduzir as taxas de conversão da floresta amazônica em áreas de reforma agrária foi a criação, em 1999, do Projeto de Desenvolvimento Sustentável (PDS) como uma modalidade fundiária que visa conciliar reforma agrária e preservação ambiental. Há controvérsias quanto aos interesses envolvidos na criação dos PDS (TORRES, 2016). Entretanto, a modalidade refletiria uma inovação nos programas de reforma agrária no Brasil, na medida em que considera fortes princípios e regras ambientais caracterizando também um novo salto de preocupações ambientais na política e na prática (BRATMAN, 2011).

A proposta dos PDS se insere em um âmbito maior de políticas de contenção do desmatamento na Amazônia. Nesse caso, a preservação ambiental seria alcançada pelo fortalecimento das atividades produtivas realizadas pelos assentados, como a agricultura familiar e o extrativismo, com práticas ecologicamente mais sustentáveis, ou seja, de baixo impacto ambiental, que, em última instância, 
contribuiriam tanto para a manutenção das famílias quanto para a contenção do desmatamento. Dessa forma, tal modalidade de assentamento se comportaria como uma política de reforma agrária de caráter sustentável.

Uma das atividades que perfazem esse viés sustentável nos PDS é o Manejo Florestal Sustentável (MFS), conceito que neste estudo abrange, além da sustentabilidade da produção florestal (notadamente de madeira para diferentes fins), os aspectos de sustentabilidade social e a preservação e conservação dos recursos naturais (MENDES, 2004).

Manejo Florestal Sustentável deve ser visto, portanto, como mantenedor de um equilíbrio entre conservação e produção de bens e serviços florestais, permitindo que a floresta se recupere e mantenha tais funções (SIST et al., 2014). Como a modalidade PDS contempla posse coletiva da Reserva Legal, o protagonismo da comunidade é desejável na gestão do Manejo Florestal de Base Comunitária (MFBC) (SIST et al., 2014), ou Manejo Florestal Comunitário (MFC) (ANGELSEN, 2010).

Ao considerarem o MFC um mecanismo para conter o desmatamento, Sist et al. (2013) reforçam que, no caso da Amazônia brasileira, o papel dos agricultores familiares é crucial, visto que também contribuem para o desmatamento, sobretudo, a partir de suas práticas agrícolas de subsistência como os roçados cultivados após pousio. Tendo em vista que pela legislação em vigor estes devem manter no mínimo $80 \%$ de suas terras em florestas, denota-se a incompatibilidade entre a lei e a prática agrícola daqueles atores, agravada pela fraca (se não nula) capacidade técnica e financeira destes se adaptarem aos requisitos ambientais (AZEVEDO-RAMOS; PACHECO, 2017; MEDINA; POKORNY, 2011; SIST et al., 2014), ou seja, apesar de promissoras e importantes, as iniciativas de MFC precisam, entre outros, tanto de maior viabilidade relativa ao marco legal, quanto de maior capacidade administrativa por parte da organização comunitária beneficiária do MFC (AZEVEDO-RAMOS; PACHECO, 2017; MEDINA; POKORNY, 2011).

Dessa forma, o sucesso das atividades de manejo florestal empreendidas em assentamentos de reforma agrária, como os PDS, perpassa pelo fortalecimento da comunidade local a fim de superar diversas adversidades que permeiam não apenas o seu cotidiano, mas a condução de uma iniciativa com demandas complexas que geralmente escapam ao domínio dos assentados.

A superação desses desafios é crucial para o êxito de demandas socioambientais, e depende, entre outros, de um amplo envolvimento dos beneficiários diretos (assentados) na atividade em questão, a fim de que possam compreender a importância desta em relação aos seus benefícios individuais e coletivos. Contudo, devido ao histórico geralmente atrelado à agricultura em bases tradicionais dos assentados, as iniciativas de MFC também devem contemplar mecanismos mais adaptativos à realidade desses grupos sociais, visando à conciliação de atividades produtivas no cotidiano das famílias.

No contexto estudado, no PDS Anapu III e IV, designado como PDS Virola-Jatobá (PDS-VJ), no município de Anapu, Pará, registram-se diferenças marcantes na adoção de estratégias de sobrevivência entre segmentos do campesinato ali residente. Embora ainda recente, o histórico de acontecimentos que marca a ocupação do PDS-VJ, inclusive a condução de uma iniciativa de manejo florestal comunitário por meio de acordo com empresa madeireira, tem fragilizado meios de vida locais e impedido a consolidação de normas sociais em comunidades camponesas em formação. Tal se deve, sobretudo, à atuação inconsistente do Estado que resulta na colisão entre direitos sociais e ambientais (BENATTI, 1999), retardando tanto o alcance de metas de justiça agrária quanto as de conservação ambiental.

No caso do PDS Virola-Jatobá, mesmo com significativo incremento da renda familiar por conta da extração florestal, via distribuição de recursos oriundos da venda de madeira, permaneceu elevada a mobilidade de assentados para fora do PDS (PORRO et al., 2018). Os que permaneceram, sobretudo os assentados pioneiros, estão mais inseridos em um contexto de ações coletivas visando conjugar a promoção da modalidade PDS à manutenção de suas práticas agrícolas de subsistência.

Diante do exposto, o presente estudo objetivou analisar se a percepção das famílias assentadas quanto à extração de madeira através de manejo florestal e a ocorrência de benefícios derivados dessa atividade no PDS Virola-Jatobá está atrelada às características dos assentados relativas ao momento de chegada ao lote, localização e, sobretudo, organização associativa. 
Após essa seção introdutória, expõem-se algumas características da área de estudo, seguidas da metodologia utilizada. Sequencialmente, apresentam-se os resultados e a discussão sobre eles, enquanto a última seção inclui as considerações finais.

\title{
2 CONTEXTUALIZAÇÃO DA ÁREA DE ESTUDO
}

O estudo foi realizado no PDS Virola-Jatobá (PDS-VJ), formalmente denominado PDS Anapu III e IV, localizado no município de Anapu, Pará, Brasil (Figura 1). O município está localizado na mesorregião do sudoeste paraense e microrregião de Altamira (SECRETARIA DE ESTADO DE PLANEJAMENTO, ORÇAMENTO E FINANÇAS, 2014). Cerca de 52\% da população, que em 2016 totalizava 26.271 habitantes, era considerada rural (IBGE 2010).

O Índice de Desenvolvimento Humano Municipal (IDH-M) de 2010 era de 0,548, considerado baixo (IBGE, 2016). O Inpe (2017) indica que em 2015 o município era coberto com cerca de $75 \%$ de floresta. O município de Anapu abarca $17 \%$ de seu território em assentamentos de reforma agrária instalados desde 1997 (PORRO et al., 2015, p. 23).

A construção da Rodovia Transamazônica e a implementação dos projetos de colonização pelo governo militar foram decisivos para a ocupação da região na qual Anapu está localizado. A chamada "integração nacional" da Amazônia ao restante do País objetivava sua ocupação por projetos de colonização e empreendimentos agropecuários. Lotes de 100 hectares às margens da rodovia eram destinados à pequena agricultura. Transversalmente à estrada, no limite de $10 \mathrm{~km}$, foram demarcados lotes de 500 ha e, após esse limite, lotes de 3.000 ha, também chamados de glebas (HÉBETTE, 2004a), destinados a grandes empreendimentos. Esse modelo de colonização incentivado pelo Instituto Nacional de Colonização e Reforma Agrária (Incra) propunha que, tanto agricultores familiares quanto fazendeiros, investissem na derrubada da floresta para a produção agropecuária. Porém, a distribuição das terras não se deu de forma equitativa.

As glebas foram conduzidas a leilões e arrematadas por empresas de capital nacional e por bancos, com os quais o poder público estabeleceu os chamados Contratos de Alienação de Terras Públicas (CATP) (IPAM, 2016; PALMEIRA, 1989; TRECCANI, 2010). Essas empresas, externas à região e ao setor agropecuário, passaram a ser os principais beneficiários de incentivos fiscais.

A política econômica implementada não contemplava os tradicionais sistemas de produção do agricultor familiar imigrante, cujos meios de vida são garantidos pela agricultura de corte-e-queima (sobretudo arroz, milho, feijão e mandioca). Conforme exposto por Hurtienne em sua descrição sobre o ciclo de fronteira, esses agricultores são:

\begin{abstract}
"minado[s] paulatinamente pelo capital mercantil explorador, títulos de propriedade inseguros, infraestrutura insuficiente, uma política agrária dirigida aos grandes estabelecimentos e pela queda dos rendimentos devido aos solos pobres em nutrientes depois da derrubada da floresta primária. No final do ciclo da fronteira, a maioria dos colonos é expulsa ou marginalizada pela grande pecuária e pelas plantações de culturas perenes" (HURTIENNE, 2005, p. 38).
\end{abstract}

As políticas foram ainda mais perversas para o campesinato amazônico, cujo entendimento de governança não coadunava com formas econômicas limitantes da autonomia no controle sobre os meios de vida, causando profundos impactos sociais e culturais (HÉBETTE, 2004a).

As condições da porção leste da Rodovia Transamazônica, onde localiza-se Anapu, sempre se apresentaram aquém da propaganda governamental do projeto de colonização. Ao contrário da Transa-Oeste, que liga Altamira e Rurópolis, caracterizada pela colonização dirigida, na Transa-Leste predominou a "colonização espontânea" de migrantes oriundos fundamentalmente do Nordeste brasileiro (BRINGEL, 2014, p. 392). As famílias migrantes que chegaram a essa região deparavam-se com a falta de infraestrutura da própria estrada, ausência de escolas, postos de saúde e assistência técnica. Posteriormente, o projeto de colonização não tardou a ser abandonado pelo governo federal. 
O estabelecimento de famílias migrantes como posseiros nas terras públicas e a expansão da concentração de terras, combinados à crescente ausência do Estado, fizeram com que os conflitos sociais e agrários não tardassem a surgir (HÉBETTE, 2004b; MENDES; PORRO, 2015). Passam a fazer parte da rotina do município de Anapu relações sociais extremamente violentas e uma forma de gestão do território com base na ilegalidade, na intimidação e agressão aos menos favorecidos (FOLHES et al. 2016, p. 305). Portanto, a configuração da atual estrutura fundiária do município de Anapu é, em parte, resultado dos projetos e políticas implementados em áreas de colonização espontânea, caracterizadas pela ampliação de latifúndios, a expansão da grilagem de terras públicas e a consequente violência e disputa por terra e recursos naturais.

Na década de 1980, o movimento social de agricultores em Anapu, apoiados pela missionária Dorothy Stang, iniciou ações de mobilização política e resistência à apropriação indevida e à grilagem de terras na região, acompanhando outros movimentos sociais da Transamazônica, cujos esforços para alcançar o desenvolvimento econômico e sustentável incluíam a integração da agricultura familiar com atividades florestais (SOUZA, 2006). Como resposta às reivindicações desse movimento social, em 1998 e 1999 o Incra realiza o recadastramento das terras em Anapu, resultando na arrecadação de parte destas, e destinação para a reforma agrária das áreas que atualmente correspondem aos Projetos de Assentamento (PA) Grotão da Onça e Pilão Poente II, e aos Projetos de Desenvolvimento Sustentável (PDS) de Anapu.

A portaria do Incra/P/№ 39, de 11 de novembro de 2002, criou os PDS Anapu III e IV (Virola-Jatobá) em terras pertencentes à União, na chamada gleba Belo Monte, tendo como principal acesso a vicinal do KM 120 Norte da Rodovia BR-230 (Transamazônica). O PDS-VJ compreende atualmente 39.602,79 ha cuja antropização cumulativa perfazia, em julho de 2015, 6,75\% dessa área (PORRO, 2016). Entretanto, devido às condições de acessibilidade, potencial produtivo e manutenção de Reserva Legal, apenas o PDS Anapu IV (módulo sul) possui "área de uso alternativo" (AUA), passível de antropização para atividades produtivas, na área se situa um total de 160 lotes. Já a área do PDS Anapu III (módulo norte), mais distante do acesso principal (Rodovia Transamazônica), é inteiramente considerada área de Reserva Legal, sendo nela permitida a atividade de manejo florestal.

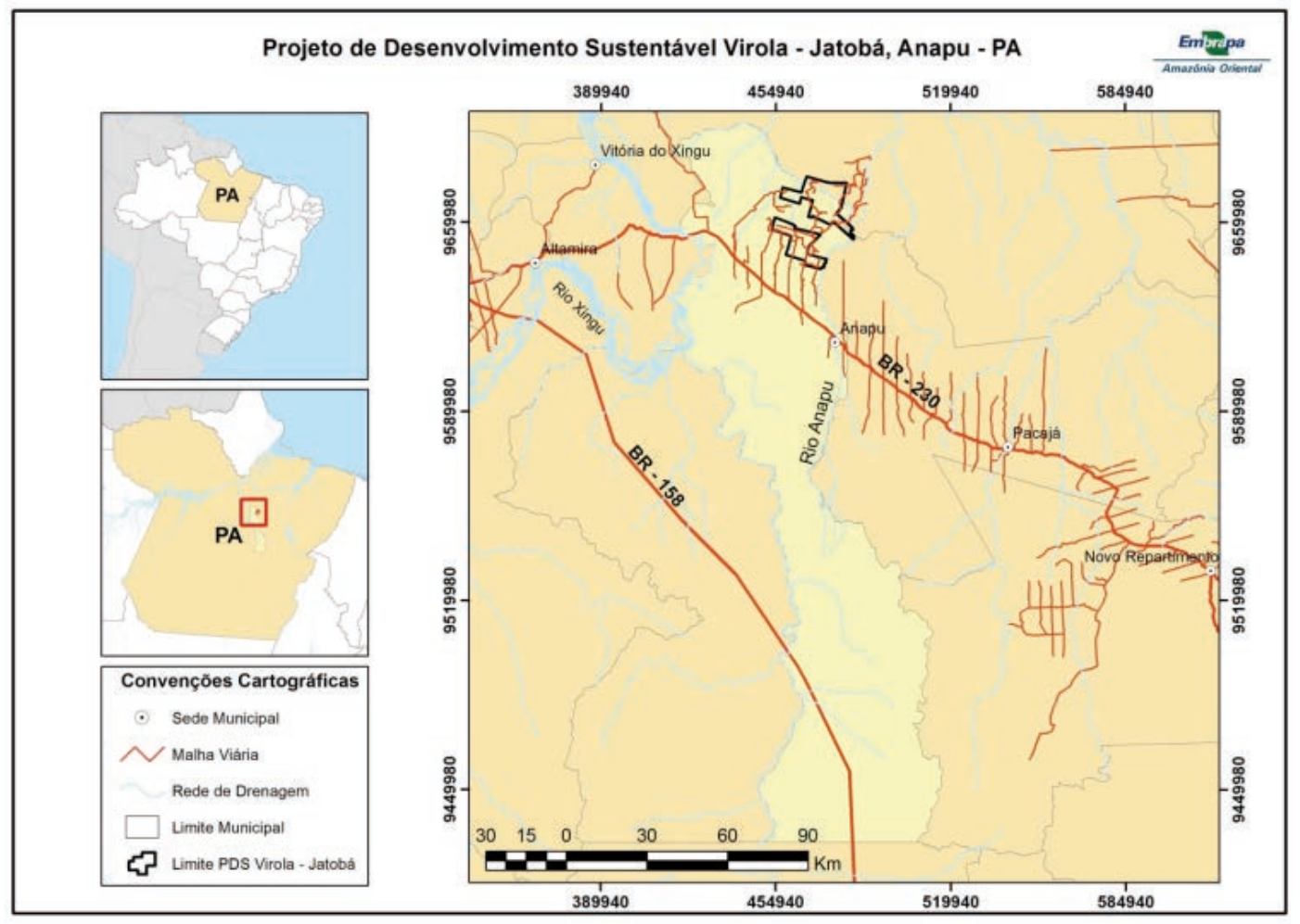

Figura 1 - Localização dos PDS Virola-Jatobá (III e IV).

Fonte: Assunção (2016). 
Nos lotes da AUA, de tamanho médio de 20 hectares, os assentados têm direito a contratos de concessão de direito real de uso (CCDRU), que, porém, somente começaram a ser emitidos pelo governo em junho de 2017. Geralmente, as áreas já antropizadas do lote estão localizadas próximas à estrada, e ao fundo destes encontram-se áreas de florestas, que limitam com a Reserva Legal, como ilustrado na Figura 2.

No PDS Virola-Jatobá, os solos são pobres se comparados aos de outras áreas na Transamazônica, fato que, somado à topografia acidentada, dificulta as práticas agrícolas em questão. Mandioca, milho e arroz, cultivados em regime de pousio, com técnicas de corte-e-queima, são destinados ao consumo e comercialização de excedentes. Tais cultivos predominam no PDS-VJ, embora a área de pastagens tenha aumentado consideravelmente na última década. Outros usos da terra observados incluem o plantio de cacau, quintais domésticos e açaizais manejados.

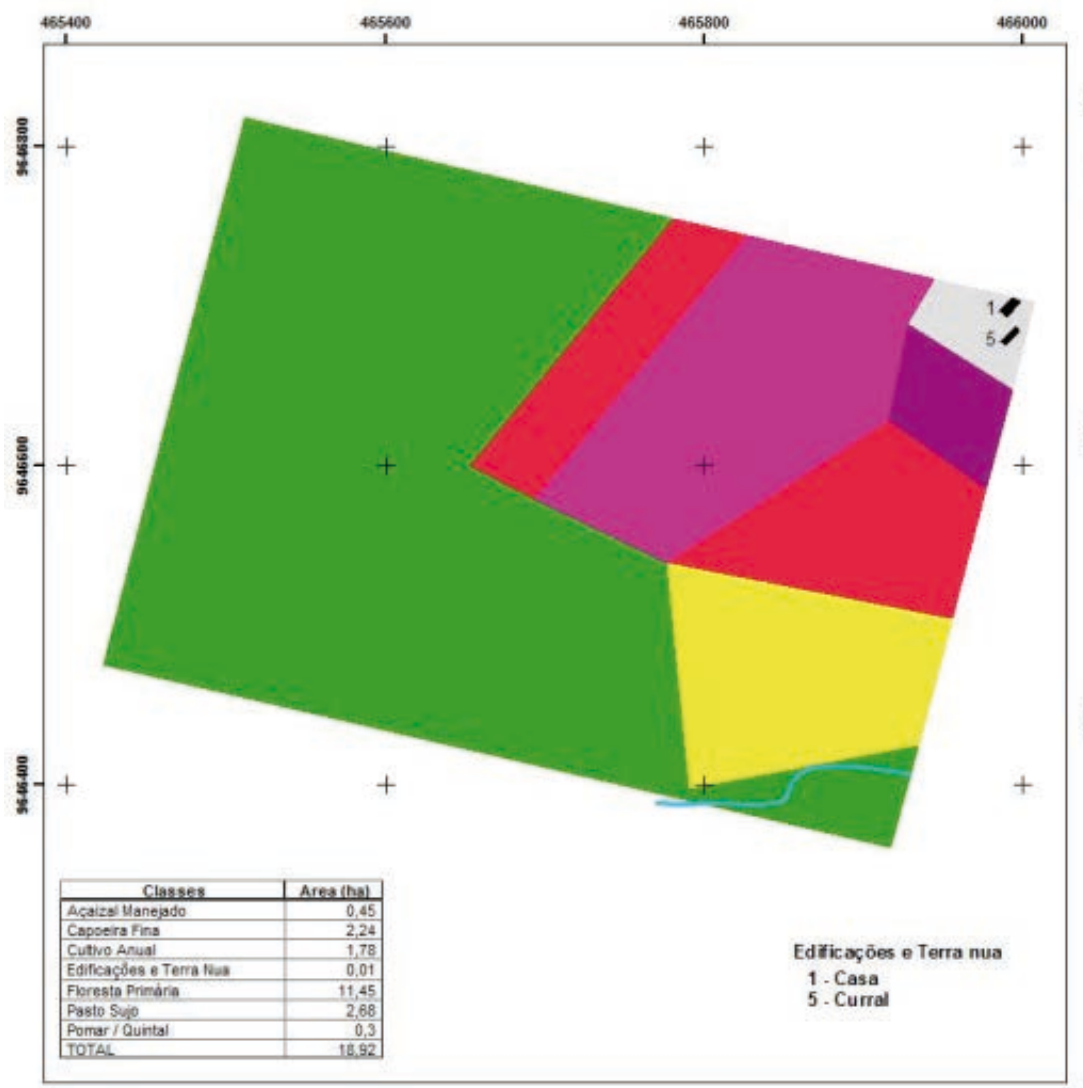

MAPA DE USO DA TERRA LOTE 54
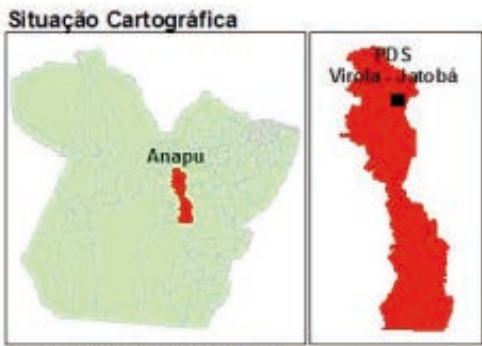

Parâmetros Cartográficos

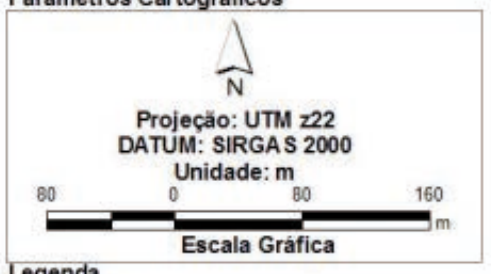

Legenda

Classes de Uso

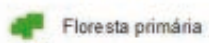

Açaizal Manejado

Capoeira fina

Cultivo anual

- Pasto sujo

Pomar / Quintal

Edificaçōes e Terra nua

Curso D'agua

Figura 2 - Croqui de lote de assentado do PDS Virola-Jatobá exemplificando uso da terra

Fonte: Assunção (2016).

A organização social mais antiga no PDS é a Associação Virola-Jatobá (AVJ), fundada em 2004. A Cooperativa de Produtores Agrícolas Orgânicos e Florestais do PDS Virola-Jatobá (Coopaf) foi estabelecida em 2008. Outras organizações surgiram recentemente: a Associação de Agricultores Liberdade do Povo (Aalp), Associação Vicinal Mutum (AVM, não formalizada) e o Grupo de Mulheres do Virola-Jatobá (Grumvija).

Durante a década de 2000, o PDS-VJ foi contemplado com recursos do Programa de Apoio ao Manejo Florestal Sustentável na Amazônia (ProManejo), promovido por instituições do governo federal, apoiadas por recursos da cooperação internacional. O ProManejo culminou com a implementação do MFC via contrato entre AVJ (detentora do projeto) e uma empresa (executora do plano de manejo), que vigorou entre 2008 e 2012. 
A ocorrência dessa atividade vislumbrava, entre outros, o combate à extração ilegal de madeira, maior geração de renda e melhor infraestrutura no assentamento. Durante os cinco anos de vigência do contrato, uma série de problemas foi gradativamente deteriorando as relações entre as partes, levando ao rompimento da parceria (PORRO et al., 2015).

A interrupção da extração de madeira via contrato comunidade / empresa (desdobramento da Instrução Normativa no 65/Incra) cria um novo contexto na medida em que impõe a execução do manejo florestal pelos próprios beneficiários da Reforma Agrária. Após dois anos de paralisação, atualmente os assentados do PDS-VJ vivenciam a retomada do manejo florestal de forma autônoma, sem a presença de uma empresa como gestora direta das ações. Desse modo, o empoderamento das organizações locais se faz urgente face às dificuldades técnico-financeiras que permeiam a condução da atividade pelas associações. $O$ fato de o manejo florestal ser atípico ao cotidiano da maior parte dos assentados, somado a uma pluralidade da comunidade relativa a posturas associativas, tempos de moradia e condições de acesso, criou um contexto de desafios a serem superados não somente para a retomada, mas também para o êxito na manutenção da atividade.

Atualmente, percebe-se também um quadro predominante de dificuldades não superadas na autonomia produtiva referente à agricultura. Tais dificuldades englobam tanto restrições naturais (relevo e solo) e socioeconômicas (capital e conhecimento técnico), quanto legais (maior restrição à conversão florestal), ou seja, percebe-se que mesmo com o incremento da renda familiar pela extração de madeira por praticamente cinco anos, muitos desafios ainda persistem na atividade agrícola, que é crucial para a manutenção dos assentados. Nesse contexto, a questão principal abordada neste artigo consiste em compreender quais as percepções dos assentados sobre as interações entre suas práticas agrícolas e a extração de madeira via o manejo florestal ali realizado.

\section{MÉTODOS}

No contexto das interações de saberes proporcionadas pela chamada pesquisa participante (BRANDÃO; BORGES, 2007; GUINDANI, 2008; SCHIMIDT, 2006), pretendeu-se esclarecer em que medida a presença do manejo florestal no assentamento influenciou decisões e a prática agrícola dos assentados. A participação do pesquisador no cotidiano dos assentados que vivenciaram o contexto da extração de madeira através da parceria com a empresa teve como objetivo elucidar posturas/estratégias produtivas relativas ao uso da terra, tanto naquele momento como atualmente. A análise de discursos e práticas referentes a uma realidade específica em última instância almejou contribuir para a construção de um saber que permita uma ação mais efetiva dos assentados para aprimorar mecanismos de intervenção sobre a realidade socioambiental em que estão inseridos.

O estudo utilizou entrevistas semiestruturadas (MARCONI; LAKATOS, 2002), análise de discurso (BARDIN, 1994; GODOY, 1995) e estatísticas descritivas. As entrevistas semiestruturadas visaram compreender o contexto anterior onde coexistiam agricultura e o MFC encerrado em 2012, verificando de que maneira a extração de madeira interferiu na condução da atividade agrícola e estratégias produtivas dos assentados, bem como a situação de tais atividades e estratégias no período em que não ocorre o manejo florestal, ou seja, vislumbrou-se elucidar o significado do MFC para as famílias e em que medida isso refletiu em suas práticas cotidianas durante e após a extração de madeira.

Foram selecionados 18 informantes (em julho de 2015) por meio de uma amostragem não probabilística por cotas utilizando as contribuições contidas em Marconi e Lakatos (2002) que definem cotas proporcionalmente distribuídas dentro de uma estratificação prévia da amostra a ser pesquisada. Nesse método há limites para tratamentos estatísticos justamente pelo seu caráter não aleatório. No caso da área de estudo, esse caráter advém de fatores, como diversidade de situações relacionadas à data de chegada (em momentos distintos), rotatividade de moradores (muitos que estavam durante o período da extração madeireira já não vivem na área e muitos que detêm o lote estavam ausentes em diversos momentos), dificuldades de comunicação e circulação e escassez de tempo para execução da pesquisa. 
Um questionário semiestruturado foi aplicado a cada entrevistado em outubro de 2015 , sendo as respostas registradas em áudio e anotações em caderno de campo. As perguntas destacadas visavam apreender aspectos relativos ao manejo florestal em si (opinião, problemas ocorridos, perspectiva de retomada e uso do recurso); aspectos relativos à produção e renda; e possíveis relações da extração de madeira com outras atividades produtivas/geradoras de renda adotadas durante e após sua ocorrência. As respostas obtidas para cada pergunta foram sistematizadas em tabelas que serviram para as análises posteriores. Nessas análises, atribuíram-se pesos (1 e 3) de acordo com a ênfase fornecida às respostas. Peso 1 refletia respostas menos enfáticas (ex. apenas respondeu sim ou não, ou não se prolongou no que citou) e peso 3 reflete situações opostas à anterior (ex. mais detalhes, maior ênfase, citado inicialmente).

A amostra selecionada envolveu apenas os assentados regulares (incluídos na relação de beneficiários do Incra), sendo que se buscou incluir assentados que atendessem concomitantemente às variáveis utilizadas para a estratificação dos entrevistados: acessibilidade do lote, momento de chegada ao lote e participação em associações internas.

A variável "momento de chegada ao lote" engloba dois grupos de famílias, sendo um formado pelos que se estabeleceram no lote até 2008, ou seja, antes da vigência do manejo florestal (chamados aqui por esse motivo de pioneiros) e outro constituído de famílias que se estabeleceram de 2009 até 2012, ou seja, durante a vigência do manejo florestal (novatos). A variável "acessibilidade do lote" foi utilizada, pois lotes apresentam variações consideráveis de distância (superiores a 20 quilômetros) e de condições de acesso (trafegabilidade das vicinais). Nesse caso, as glebas indicadas como favoráveis (128, 129 e 130) possuem tanto menor distância ao acesso principal do PDS-VJ (Rodovia Transamazônica) quanto melhor condição de tráfego da vicinal, situações inversas em relação às glebas indicadas como desfavoráveis (107 e 132).

Em relação à variável "participação em Associações internas" destaca-se que tais organizações representam legalmente os assentados no intuito de viabilizar e garantir suas demandas perante os órgãos públicos, bem como possibilitar uma consolidação do assentamento em suas demandas sociais, econômicas e ambientais. A associação comunitária pioneira, chamada Associação Virola-Jatobá (AVJ) tem origem vinculada ao período de criação do PDS, isto é, há mais de dez anos. Contudo, alguns meses antes da realização das entrevistas, o referido assentamento vivenciou o início de um processo inédito de formação de duas novas associações: Associação de Agricultores Liberdade do Povo (AALP, já formalizada) e Associação Vicinal Mutum (AVM, não formalizada). Ambas divergem em vários temas em relação à atuação da AVJ, até então única entidade representativa dos assentados.

A Tabela 1 apresenta a composição da amostra para coleta dos dados primários conforme as variáveis acima descritas.

Tabela 1 - Composição da amostra para entrevistas

\begin{tabular}{|c|c|c|c|c|c|}
\hline \multirow{4}{*}{ Acessibilidade do lote } & \multicolumn{4}{|c|}{ Momento de ocupação no lote } & \multirow[b]{4}{*}{ Total } \\
\hline & \multirow{2}{*}{\multicolumn{2}{|c|}{$\begin{array}{c}2002 \text { a } 2008 \\
\text { (anterior ao manejo) } \\
\text { Associação }\end{array}$}} & \multirow{2}{*}{\multicolumn{2}{|c|}{$\begin{array}{c}2009 \text { a } 2012 \\
\text { (durante o manejo) } \\
\text { Associação }\end{array}$}} & \\
\hline & & & & & \\
\hline & AVJ & não AVJ & AVJ & não AVJ & \\
\hline Favorável (Glebas 128, 129 e 130) & 3 & 2 & 3 & 2 & 10 \\
\hline Desfavorável (Glebas 107 e 132) & 1 & 3 & 2 & 2 & 8 \\
\hline Total & 4 & 5 & 5 & 4 & 18 \\
\hline
\end{tabular}




\section{RESULTADOS}

Nesta seção são apresentados e analisados os resultados de perguntas aplicadas em campo. As tabelas apresentam as frequências das respostas obtidas a cada pergunta (indicadas entre parênteses após cada resposta), e o valor ponderado referente a cada estrato de entrevistados, aplicando-se os pesos conforme a ênfase de suas respostas.

\subsection{OPINIÃO DOS ASSENTADOS SOBRE O MANEJO FLORESTAL}

Por meio das respostas a esta pergunta (Tabela 2) constatou-se a opinião e ênfase da maioria referindose à atividade de manejo florestal como importante para a renda familiar nas quatro situações analisadas (localização do lote/tempo de chegada), independente da cisão da comunidade pela perspectiva de formação de duas novas associações. Cabe destacar que fora do âmbito da renda, as opiniões sobre manejo florestal com um viés socioambiental foram predominantes entre os sócios da AVJ. Do mesmo modo, posturas mais avessas ou de indiferença à atividade foram exclusivas dos entrevistados das demais associações.

Tabela 2 - Opinião dos assentados sobre o manejo florestal

\begin{tabular}{|c|c|c|c|c|c|c|c|c|c|}
\hline \multirow{3}{*}{$\begin{array}{c}\text { Tempo de chegada ao PDS } \\
\text { Condições de acesso } \\
\text { Associações: membro da AVJ }\end{array}$} & \multicolumn{4}{|c|}{ pioneiros } & \multicolumn{4}{|c|}{ novatos } & \multirow[b]{3}{*}{ Total } \\
\hline & \multicolumn{2}{|c|}{ favorável } & \multicolumn{2}{|c|}{ desfavorável } & \multicolumn{2}{|c|}{ favorável } & \multicolumn{2}{|c|}{ desfavorável } & \\
\hline & Sim & Não & Sim & Não & Sim & Não & Sim & Não & \\
\hline $\begin{array}{l}\text { a. Importante na melhora da renda } \\
\text { familiar (13) }\end{array}$ & 4 & 4 & 3 & 4 & 6 & 6 & 3 & 3 & 33 \\
\hline $\begin{array}{l}\text { b. Importante para benefícios como } \\
\text { evitar retirada ilegal de madeira, } \\
\text { manutenção de vicinais, aprendizado: } \\
\text { uso da floresta (3) }\end{array}$ & 3 & & & & 3 & & 3 & & 9 \\
\hline $\begin{array}{l}\text { c. Importante fonte de recursos para } \\
\text { associação (3) }\end{array}$ & 1 & & 3 & & & 3 & & & 7 \\
\hline $\begin{array}{l}\text { d. Ruim, pois atrai regras mais rígidas } \\
\text { no uso do lote (2) }\end{array}$ & & & & 3 & & & & 3 & 6 \\
\hline e. Indiferente (foco na agricultura) (1) & & & & 1 & & & & & 1 \\
\hline
\end{tabular}

Fonte: Elaboração própria.

\subsection{O QUE DEVERIA MUDAR NA EXECUÇÃO DO MANEJO FLORESTAL, CASO SEJA RETOMADO?}

Apesar da pergunta anterior indicar forte apoio ao manejo florestal, observou-se que os entrevistados reconhecem muitos problemas na experiência finalizada (Tabela 3). Tais percepções giraram em torno justamente da necessidade de maior e melhor controle administrativo por parte daqueles que thes representavam - a associação - tanto sobre a execução da atividade quanto em relação ao recurso recebido (e seu consequente uso).

As respostas a essa pergunta indicam maior diversidade para os residentes pioneiros, o que deve ser reflexo de um maior conhecimento destes devido ao tempo de moradia e de mínima inserção dos demais no contexto da atividade. De modo geral, é latente a percepção de falhas que envolveram a participação da organização comunitária durante a extração de madeira. 
Tabela 3-O que deveria mudar na execução do manejo florestal, caso seja retomado

\begin{tabular}{|c|c|c|c|c|c|c|c|c|c|}
\hline \multirow{3}{*}{$\begin{array}{c}\text { Tempo de chegada ao PDS } \\
\text { Condições de acesso } \\
\text { Associações: membro da AVJ }\end{array}$} & \multicolumn{4}{|c|}{ pioneiros } & \multicolumn{4}{|c|}{ novatos } & \multirow[b]{3}{*}{ Total } \\
\hline & \multicolumn{2}{|c|}{ favorável } & \multicolumn{2}{|c|}{ desfavorável } & \multicolumn{2}{|c|}{ favorável } & \multicolumn{2}{|c|}{ desfavorável } & \\
\hline & Sim & Não & Sim & Não & Sim & Não & Sim & Não & \\
\hline $\begin{array}{l}\text { a. Melhoria na administração da } \\
\text { atividade pela Associação (5) }\end{array}$ & & & & & 6 & 3 & 3 & 3 & 15 \\
\hline $\begin{array}{l}\text { b. Melhoria/mudança no uso/ gestão } \\
\text { do recurso recebido pela Associação } \\
\text { (6) }\end{array}$ & 7 & & & 3 & & 3 & 1 & & 14 \\
\hline $\begin{array}{l}\text { c. Maior transparência na execução } \\
\text { da atividade ( } 3 \text { ) }\end{array}$ & & 4 & & & & 1 & & & 5 \\
\hline d. Menor burocracia na aprovação (1) & & & 3 & & & & & & 3 \\
\hline $\begin{array}{l}\text { e. Menor desperdício de madeira } \\
\text { descartada (1) }\end{array}$ & & & & 3 & & & & & 3 \\
\hline $\begin{array}{l}\text { f. Maior envolvimento da comunidade } \\
\text { (1) }\end{array}$ & & & 3 & & & & & & 3 \\
\hline $\begin{array}{l}\text { g. Auxiliar na redução da burocracia - } \\
\text { uso do lote (1) }\end{array}$ & & & & 3 & & & & & 3 \\
\hline $\begin{array}{l}\text { h. Rateio a quem de direito / aumento } \\
\text { do valor recebido por assentado (2) }\end{array}$ & 1 & & 1 & & & & & & 2 \\
\hline i. Nada (2) & & & & 1 & & & & 1 & 2 \\
\hline
\end{tabular}

Fonte: Elaboração própria.

\subsection{PARTICIPAÇÃO DOS ASSENTADOS NO MANEJO FLORESTAL}

Percebe-se que mesmo com os problemas citados, a maioria expressou desejo de trabalhar na atividade naquele momento (Tabela 4), tal desejo advindo da possibilidade de aprendizado e renda, que, neste último caso, se explica pela tendência de não haver ainda um uso consolidado do lote. Essa resposta foi dada, sobretudo, pelo grupo dos novatos (independente da localização), sendo constatada participação nula na atividade entre eles. Ao inverso, os que participaram efetivamente da atividade eram pioneiros, majoritariamente membros da AVJ. Isso denota a importância do tempo na organização comunitária em prol da proposta do PDS, na medida em que há maior tendência de inserção nas ações implementadas e, consequentemente, de maior conscientização quanto à consolidação dessa modalidade fundiária. 
Tabela 4 - Participação dos assentados no manejo florestal

\begin{tabular}{|c|c|c|c|c|c|c|c|c|c|}
\hline \multirow{3}{*}{$\begin{array}{c}\text { Tempo de chegada ao PDS } \\
\text { Condições de acesso } \\
\text { Associações: membro da AVJ }\end{array}$} & \multicolumn{4}{|c|}{ pioneiros } & \multicolumn{4}{|c|}{ novatos } & \multirow[b]{3}{*}{ Tota } \\
\hline & \multicolumn{2}{|c|}{ favorável } & \multicolumn{2}{|c|}{ desfavorável } & \multicolumn{2}{|c|}{ favorável } & \multicolumn{2}{|c|}{ desfavorável } & \\
\hline & Sim & Não & Sim & Não & Sim & Não & Sim & Não & \\
\hline $\begin{array}{l}\text { a. Nenhuma (não houve convite - } \\
\text { aceitaria) (9) }\end{array}$ & 1 & & & 3 & 4 & 6 & 1 & 2 & 17 \\
\hline $\begin{array}{l}\text { b. Nenhuma (não houve convite - } \\
\text { não aceitaria) (4) }\end{array}$ & 1 & & & 4 & 1 & & & & 6 \\
\hline $\begin{array}{l}\text { c. Participou realizando vistorias (na } \\
\text { área do manejo) (2) }\end{array}$ & 3 & & 3 & & & & & & 6 \\
\hline $\begin{array}{l}\text { d. Nenhuma (convidado, não aceitou } \\
\text { - trabalho no lote) (3) }\end{array}$ & 1 & 3 & & & & & 1 & & 5 \\
\hline $\begin{array}{l}\text { e. Trabalhou no primeiro inventário e } \\
\text { romaneios (1) }\end{array}$ & & 3 & & & & & & & 3 \\
\hline $\begin{array}{l}\text { f. Integrou discussões para } \\
\text { elaboração do projeto de manejo } \\
\text { florestal (1) }\end{array}$ & 3 & & & & & & & & 3 \\
\hline
\end{tabular}

Fonte: Elaboração própria.

\subsection{APLICAÇÃO DO RECURSO RECEBIDO DO MANEJO FLORESTAL PELOS ASSENTADOS}

O investimento do recurso recebido ocorreu prioritariamente em alternativas que envolvem o bemestar da família (basicamente transporte e moradia), em detrimento das atividades geradoras de renda, reflexo da urgência em suprir necessidades básicas, como pode ser verificado na Tabela 5.

Verificou-se uma maior heterogeneidade de investimentos no grupo dos pioneiros de glebas de acesso favorável, induzindo a certo relaxamento daquelas necessidades imediatas, o que pode estar relacionado a uma maior resiliência da família/assentado. Contudo, a precariedade generalizada que permeia o assentamento indica necessidade, entre outros, do fortalecimento de ações coletivas via organização comunitária no intuito de amenizá-la a partir das opções possíveis.

Depreende-se disso que políticas públicas adequadas reduziriam a precariedade e, por consequência, aumentariam a possibilidade de investimentos consistentes (via recurso recebido) nas atividades produtivas desempenhadas pelos assentados, o que contribuiria para consolidar o assentamento destes. 
Tabela 5 - Aplicação do recurso recebido do manejo florestal pelos assentados

\begin{tabular}{|c|c|c|c|c|c|c|c|c|c|}
\hline \multirow{3}{*}{$\begin{array}{c}\text { Tempo de chegada ao PDS } \\
\text { Condições de acesso } \\
\text { Associações: membro da AVJ }\end{array}$} & \multicolumn{4}{|c|}{ pioneiros } & \multicolumn{4}{|c|}{ novatos } & \multirow[b]{3}{*}{ Tota } \\
\hline & \multicolumn{2}{|c|}{ favorável } & \multicolumn{2}{|c|}{ desfavorável } & \multicolumn{2}{|c|}{ favorável } & \multicolumn{2}{|c|}{ desfavorável } & \\
\hline & Sim & Não & Sim & Não & Sim & Não & Sim & Não & \\
\hline a. Motocicleta (11) & 3 & 3 & & 4 & 6 & 3 & 6 & 6 & 31 \\
\hline b. Alimentação (9) & 3 & 4 & & 2 & 1 & 3 & 1 & 1 & 15 \\
\hline c. Bens de consumo duráveis (6) & 4 & & & 3 & 1 & 3 & 3 & & 14 \\
\hline d. Construção / reforma da casa (4) & 3 & 1 & & & 3 & & 3 & & 10 \\
\hline e. Infraestrutura básica (água/luz) (3) & & 3 & & 3 & & 3 & & & 9 \\
\hline $\begin{array}{l}\text { f. Equipamentos/ insumos de trabalho } \\
\text { (3) }\end{array}$ & 3 & & & 6 & & & & & 9 \\
\hline g. Pagamento de dívidas (2) & & & & & 1 & & & 3 & 4 \\
\hline h. Pagamento de diárias (lavoura) (1) & & & 3 & & & & & & 3 \\
\hline $\begin{array}{l}\text { i. Outros: Peças para carro, } \\
\text { passagens ou terreno ( } 3 \text { ) }\end{array}$ & 1 & 1 & 1 & & & & & & 3 \\
\hline
\end{tabular}

\subsection{RENDA MONETÁRIA DA FAMÍLIA}

Indagou-se também em que momento a renda do entrevistado seria maior, se durante o período de condução da extração de madeira ou atualmente (Tabela 6). Nesse caso, o conjunto de respostas não foi ponderado, isto é, os valores que constam na tabela, correspondem ao número de respostas. Constatase a importância da extração de madeira para a renda da maioria dos entrevistados, pois mais de $80 \%$ consideraram ter renda maior durante tal período devido ao recurso recebido, enquanto somente um entrevistado considerou sua renda atual superior. Esse fato reflete, portanto, inconsistências na geração de renda pelos assentados, que, por sua vez, se fazem sentir na manutenção da comunidade.

Tabela 6 - Renda monetária da família

\begin{tabular}{|c|c|c|c|c|c|c|c|c|}
\hline \multirow{3}{*}{$\begin{array}{c}\text { Tempo de chegada ao PDS } \\
\text { Condições de acesso } \\
\text { Associações: membro da AVJ }\end{array}$} & \multicolumn{4}{|c|}{ pioneiros } & \multicolumn{4}{|c|}{ novatos } \\
\hline & \multicolumn{2}{|c|}{ favorável } & \multicolumn{2}{|c|}{ desfavorável } & \multicolumn{2}{|c|}{ favorável } & \multicolumn{2}{|c|}{ desfavorável } \\
\hline & Sim & Não & Sim & Não & Sim & Não & Sim & Não \\
\hline $\begin{array}{l}\text { a. Renda maior durante o } \\
\text { manejo (15) }\end{array}$ & 3 & 2 & 1 & 2 & 2 & 2 & 2 & 1 \\
\hline $\begin{array}{l}\text { b. Renda semelhante ao período } \\
\text { do manejo (2) }\end{array}$ & & & & 1 & & & & 1 \\
\hline c. Renda maior atualmente (1) & & & & & 1 & & & \\
\hline
\end{tabular}


A partir de entrevistas realizadas com lideranças das associações em formação (AALP e AVM), podese depreender que estas tratam o manejo florestal com restrições (incluindo a possibilidade de sua retomada no PDS-VJ), defendem maior liberdade de uso do lote (ante as restrições que envolvem um PDS), e criticam a representatividade da AVJ (gestões atual e anterior) tanto em relação a problemas ocorridos no manejo florestal anterior quanto a seu envolvimento na provável retomada da atividade, assim como em relação às dificuldades em geral enfrentadas pelos assentados. De início, percebe-se que alguns desses posicionamentos extrapolariam o previsto na modalidade PDS, como a liberdade de uso do lote e, portanto, seriam a priori inviáveis em sua efetivação.

\section{DISCUSSÃO}

Avaliando o contexto associado ao período de manejo florestal (2008-2012) no PDS-VJ, com base nas respostas obtidas, percebeu-se que, com o fim da extração de madeira e, consequentemente, da renda auferida pelos assentados oriunda de sua venda, ocorre significativa redução da renda familiar, e, por conseguinte, um quadro de dificuldades no cotidiano dessas famílias. Esse fato apresenta correlação tanto com a predominante opinião dos entrevistados indicando a relevância do manejo florestal como provedor de receita para eles quanto à situação de que mesmo reconhecendo diversos problemas na execução da atividade, sobretudo relativos à gestão, a maioria indicou a disposição de ter trabalhado nela, especialmente pela provisão de aprendizado e renda.

A prioridade concedida ao incremento da renda denota dificuldades na manutenção dos assentados devido à não consolidação do uso do lote e carências de infraestrutura do assentamento, assim como uma ainda incipiente conscientização em relação à provisão de serviços ambientais. Tal quadro de colisão entre direitos sociais e ambientais, que acaba por retardar tanto o alcance de metas de justiça agrária quanto às de conservação ambiental, é compreensível quando verificamos o histórico do grupo social envolvido, com predominância de migrantes nordestinos que já vinham de situações anteriores de expropriação. Disso resulta que muitas das vezes aquele recurso foi aplicado para satisfazer necessidades de consumo e bem-estar da família assentada (ex. motos, alimentos, utensílios domésticos, reformas na moradia, etc.), o que, de certa forma, justifica o não investimento direto em atividades produtivas.

A conjugação de fatores, incluindo as precárias condições no assentamento (habitação, energia, água, transporte, etc.), dificuldades nas atividades produtivas, retração da renda pós-manejo florestal, e problemas percebidos pela comunidade na execução deste (envolvendo a AVJ e a empresa), criou um ambiente favorável a críticas e novas posturas que se reflete em um movimento recente de desagregação dos assentados e a proposta de criação de novas associações (AVM e AALP). Percebeu-se, contudo, que integrantes dessas novas associações ainda são formalmente membros da AVJ e que pretendem manter tal vínculo por esta ainda ser a única representante legal dos assentados nas relações com órgãos públicos, o que, portanto, reflete uma segurança na obtenção de algum benefício futuro.

Essa nova perspectiva gera um ambiente que tende ao atrito em relação ao que deve ser foco de investimentos, bem como ao que não deve ser incentivado. Surgem, com as novas associações, discursos contrários ou de restrições à retomada do manejo florestal, e de maior autonomia do assentado no uso do seu lote para a implantação de novas atividades. Percebe-se o aumento nos casos de entrevistados que desejavam investir na pecuária, que, na visão de muitos, seria a alternativa para fixação e sucesso do assentado, permitindo maior estabilidade na geração de renda, comparada à agricultura.

Apesar de não ser a atividade foco da modalidade PDS, o próprio Incra não somente autorizou, mas durante um período também incentivou a pecuária como alternativa de renda ante as dificuldades enfrentadas pelos assentados com o fim do recurso oriundo da extração de madeira. Tal opção, atrelada às mencionadas dificuldades, alimenta o discurso, especialmente nas novas associações, a favor da atividade, ressaltando que muitos desses assentados já iniciaram a formação de pastos em seus lotes, apesar de não possuírem gado. 
Nesses casos, a efetivação da pecuária esbarra justamente na restrição financeira que poderia ser superada com a concessão de linhas de créditos bancários agora disponíveis para tal. Esse cenário, incentivado pelo próprio Estado, se apresenta como potencialmente de risco para a consolidação ambiental do referido assentamento, dado tanto o caráter dessa atividade na Amazônia - geralmente insustentável - quanto à contradição da atividade para com a modalidade do assentamento em questão (PDS).

O movimento recente de ruptura da comunidade não está, portanto, desconectado do histórico atual desse assentamento, e que os discursos para tal cisão encontram certo respaldo em fatos recentes, embora outros se apresentem infundados. Tais discursos (válidos ou não) têm se concretizado em ações cotidianas que se tornam ao mesmo tempo mais diversas e complexas, dificultando a construção de consensos necessários ao fortalecimento da comunidade, requisito primordial na busca por um maior empoderamento do grupo social, e para a consequente provisão de benefícios para seus membros. Um maior diálogo a partir da acessibilidade mútua seria pertinente, podendo reverter positivamente para a comunidade a diversidade de discursos em um contexto das possibilidades e limitações reais.

O fato de os entrevistados mais antigos e/ou associados apenas à AVJ terem apresentado, de modo geral, posturas e discursos que representam uma maior imersão no manejo florestal (participação, aceitabilidade, reconhecimento do papel da atividade de manejo, etc.) é um indicativo de que a estabilidade no lote e o maior envolvimento na atividade são requisitos importantes que podem funcionar como indutores de um panorama interno menos adverso e paralelamente mais agregador rumo ao necessário protagonismo da comunidade. Tais demandas são cruciais não apenas para viabilizar o MFC enquanto uma atividade inovadora e desejável nessa modalidade de assentamento, mas também por representar a autonomia na manutenção da comunidade, ambas situações simbolizando uma certa ruptura diante do histórico socioeconômico e ambiental, respectivamente, de caráter excludente e insustentável na escala regional.

Deduz-se, portanto, que apesar da complexidade e desafios postos ao manejo florestal, tal atividade se revela importante tanto no aspecto ambiental em si, a partir da redução do desmatamento, quanto para o bem-estar da comunidade em questão, por meio de oportunidades de geração de renda. Nesse contexto, o mosaico ideológico e organizacional, somado às dificuldades que ainda marcam o cotidiano dos assentados, requisitará esforços ainda maiores destes e das instituições públicas envolvidas no sentido de viabilizar a consolidação dos objetivos sociais e ambientais que perfazem essa modalidade de assentamento.

\section{CONSIDERAÇÕES FINAIS}

O estudo de caso do PDS-VJ indica que, apesar de louváveis, iniciativas como o manejo florestal, que visam mitigar problemas ambientais (desmatamento) e sociais na Amazônia, ainda apresentam muitos desafios. Tais desafios, no caso analisado, perpassam tanto pela atuação do Estado quanto do grupo envolvido. No caso do Estado, destaca-se, sobretudo, a insuficiência de infraestrutura de serviços básicos no assentamento e o complexo marco legal para a execução do manejo florestal, que não considera a capacidade técnica dos que conduzirão a atividade.

Ambas as situações se refletem nos desafios impostos aos assentados na medida em que geram considerável dificuldade de êxito nas ações empreendidas em uma comunidade já vulnerável. Tais fatos puderam ser detectados quando a maioria concedeu importância à extração de madeira pela renda propiciada e indicaram, sobretudo, problemas na execução pela empresa, e administração da atividade por parte da associação que os representava na experiência já finalizada.

A essas adversidades soma-se o recente processo de cisão da comunidade em associações, que, por terem posturas contrárias ao manejo florestal, acabam criando um contexto de maior incerteza nas ações que visem o retorno dessa atividade. Faz-se assim urgente o esforço da comunidade no sentido de estabelecer ações coletivas harmônicas visando, apesar das divergências ideológicas, pactuar uma agenda consolidada em prol do grupo como um todo. 
A AVJ, enquanto instituição mais antiga e com histórico atrelado ao manejo florestal no PDS-VJ, tem um papel primordial visando à congregação de discursos e práticas junto às demais associações, na medida em que ainda apresenta maior legitimidade na representação dos assentados perante os órgãos públicos. Essa empreitada se revela pertinente para o sucesso de ações que visem o bem-estar comum. Estas, por sua vez, se refletiriam na viabilização tanto do PDS quanto do manejo florestal comunitário, com ganhos consistentes em demandas socioambientais.

O alcance desses objetivos seria bastante representativo na medida em que comporta um certo ineditismo das políticas fundiárias atreladas a demandas ambientais diante do histórico regional e que, apesar das peculiaridades da área de estudo, poderia servir de impulso a um cenário cada vez mais favorável à superação das adversidades que permeiam aquelas demandas na Amazônia.

Concluímos que, para a efetividade do manejo florestal comunitário e do PDS como um todo, a consolidação de normas sociais internas, que articulem as atividades tradicionalmente realizadas pelos assentados com o manejo florestal, é condição essencial e prioritária. Para cumprir esse condicionante, as organizações locais proponentes do MFC e o governo, como ente promotor, devem apreender quais variáveis contextuais incentivam e quais limitam cada um dos segmentos divergentes na criação e adoção das normas sociais a serem compartilhadas.

\section{NOTAS}

${ }^{1}$ Serviços ambientais são benefícios que as pessoas obtêm direta ou indiretamente, por meio dos ecossistemas, para sustentar a vida no planeta. A Avaliação Ecossistêmica do Milênio da ONU, publicada em 2005, classificou serviços ambientais como de provisão, regulação, suporte e culturais.

${ }^{2}$ Sociodiversidade refere-se à pluralidade sociocultural que resulta da manutenção de sistemas sociais distintos (NEVES, 1999).

\section{REFERÊNCIAS}

ANGELSEN, A. Policies for reduced deforestation and their impact on agricultural production. PNAS. v. 107, n. 46, p. 19639-19644, 2010.

ASSUNÇÃO, H. N. Interações entre agricultura e manejo florestal: uma análise do uso da terra, meios de vida e sustentabilidade no projeto de desenvolvimento sustentável Virola-Jatobá em Anapu (PA). 2016. 161 p. Dissertação (Mestrado em Ciências Ambientais) - Universidade Federal do Pará, Belém, 2016.

AZEVEDO-RAMOS, C.; PACHECO, J. Economia florestal comunitária e familiar na Amazônia. In: PEZUTTI, J.; AZEVEDO-RAMOS, C. (Org.). Desafios amazônicos. Belém, PA: Universidade Federal do Pará. Núcleo de Altos Estudos Amazônicos, 2017. (no prelo). (Série Desenvolvimento e Sustentabilidade).

BARDIN, L. Análise de conteúdo. Lisboa: Edições Setenta, 1994.

BENATTI, J. H. A criação de unidades de conservação em áreas de apossamento de populações tradicionais. Novos cadernos Naea, v. 1, n. 2, 2014.

BRANDÃO, C. R.; BORGES, M. C. A pesquisa participante: um momento da educação popular. Revista de Educação Popular, v. 6, p. 51-62, 2007.

BRANDÃO JÚNIOR, A.; SOUZA JÚNIOR, C. Deforestation in land reform settlements in the Amazon. State of the Amazon. Imazon, n. 7, p. 1-4, 2006.

BRASIL. Ministério do Meio Ambiente (MMA). Biomas: Amazônia. 2016. Disponível em: <http://www. mma.gov.br/biomas/amaz\%C3\%B4nia>. Acesso em: 16 dez. 2016. 
BRATMAN, E. Villains, victims, and conservationists? Representational frameworks and sustainable development on the transamazon highway. Human Ecology, v. 39, p. 441-453, 2011.

BRINGEL, F. O. Territorialização camponesa e fronteira agrária - o caso do Projeto de Desenvolvimento Sustentável (PDS) Esperança em Anapu - Pará - Brasil. Boletim Gaúcho de Geografia, v. 41, n. 2, p. 384-403. 2014.

FEARNSIDE, P. M. Desmatamento na Amazônia: dinâmica, impactos e controle. Acta Amazônica, v. 36, n. 3, p. 395-400, 2006.

FOLHES, R. et al. Conflitos fundiários e reforma agrária na Amazônia: experiência do PDS Esperança no município de Anapu. Passages de Paris, v. 12, p. 304-318. 2016.

GODOY, A. S. Pesquisa qualitativa: tipos fundamentais. Revista de Administração de Empresas, São Paulo, v. 35, n. 3, p. 20-29, maio/jun. 1995.

GUINDANI, J. F. Perspectivas e desafios entre a dupla ruptura epistemológica e pesquisa participante. Visão Global, v. 11, n. 1, p. 79-96, 2008.

HÉBETTE, J. Cruzando a fronteira: 30 anos de estudo do campesinato na Amazônia. Volume 1 Migração, colonização e ilusões de desenvolvimento. Belém: Edufpa. 2004a.

Cruzando a fronteira: 30 anos de estudo do campesinato na Amazônia. Volume 3 - Os grandes projetos. A questão ambiental: problemas e propostas. Belém: Edufpa. 2004b.

HURTIENNE, T. Agricultura familiar e desenvolvimento rural sustentável na Amazônia. Novos Cadernos Naea, v. 8, n. 1, p. 19-71. 2005.

INSTITUTO BRASILEIRO DE GEOGRAFIA E ESTATÍSTICA. Cidades. 2016. Disponível em: <https://cidades. ibge.gov.br/brasil/pa/anapu/panorama>. Acesso em: 04 maio 2017.

INSTITUTO DE PESQUISA AMBIENTAL DA AMAZÔNIA. 2016. A Grilagem de Terras Públicas na Amazônia. Disponível em: <http://www.mma.gov.br/estruturas/168/_publicacao/168_ publicacao30012009114114.pdf>. Acesso em: 31 jul. 2018.

INSTITUTO NACIONAL DE PESQUISAS ESPACIAIS. Projeto Prodes:monitoramento da floresta amazônica brasileira por satélite. 2017. Disponível em: <http://www.obt.inpe.br/OBT/assuntos/programas/ amazonia/prodes>. Acesso em: 15 out. 2017.

INSTITUTO NACIONAL DE PESQUISAS ESPACIAIS. Projeto Prodes: desflorestamento nos municípios da Amazônia Legal para o ano de 2015. 2017. Disponível em: <http://www.dpi.inpe.br/prodesdigital/ prodesmunicipal.php>. Acesso em: 10 mar. 2017.

MARCONI, M. A.; LAKATOS, E. M. Técnicas de pesquisa. São Paulo: Atlas, 2002. 282 p.

MEDINA, G.; POKORNY, B. Avaliação financeira do manejo florestal comunitário. Novos Cadernos Naea, v. 14, n. 2, p. 25-36, 2011.

MENDES, J.; PORRO, N. M. Conflitos sociais em tempos de ambientalismo: direito vivo à terra em assentamentos com enfoque conservacionista. Ambiente \& Sociedade, v. 18, n. 2, p. 97-114. 2015.

MENDES, J. B. Incentivos e mecanismos financeiros para o manejo florestal sustentável na Região Sul do Brasil. Relatório. FAO - Food and Agriculture Organization of the United Nations: Curitiba, 2004. Disponível em: <http://www.fao.org/forestry/12000-09ec4e1c04ebfcd232f76c89136cadcf.pdf>. Acesso em: 05 abr. 2018.

NEVES, W. A. Antes de Cabral: a Arqueologia e a Sociodiversidade no passado. Revista USP, n. 44, p. 6-9, 1999. 
PALMEIRA, M. Modernização, Estado e questão agrária. Estudos Avançados, v. 3, n. 7, p. 87-108. 1989.

PARÁ. Secretaria de Estado de Planejamento, Orçamento e Finanças. Anapu: estatística municipal. 44 p. 2014. Disponível em: <http://www.fapespa.pa.gov.br/upload/Arquivo/anexo/650. pdf?id=1527889137>. Acesso em: 08 ago. 2016.

PORRO, R. Proposta para regularização e licenciamento ambiental da área de uso alternativo nas parcelas do PDS Anapu IV (PDS Virola-Jatobá). Belém: Embrapa Amazônia Oriental (Documento não publicado, submetido à Secretaria de Meio Ambiente e Sustentabilidade do Estado do Pará em 19 de outubro de 2016).

PORRO, R. et al. Collective action and forest management: institutional challenges for enhanced socialecological systems of the environmental agrarian reform in Anapu, Brazilian Amazon. International Forestry Review, v. 17, p. 20-37, 2015.

PORRO, R. et al. Mobilidade, renda e desmatamento: diversidade e resiliência do campesinato em assentamento com ênfase ambiental em Anapu, Amazônia Oriental. Revista de Economia e Sociologia Rural. (Aceito em fevereiro de 2018).

SALATI, E.; VOSE, P. Amazon Basin: a system in equilibrium. Science, New Series, v. 225, n. 4658, p. 129138, 1984.

SCHMIDT, M. L. S. Pesquisa participante: alteridade e comunidades interpretativas. Ensaios indisciplinados: aconselhamento psicológico e pesquisa participante. Psicologia USP, Instituto de Psicologia da Universidade de São Paulo, São Paulo, v. 17, n. 2, p. 11-41, 2006.

SIST, P.; MAZZEI, L.; SABLAYROLLES, P. A diminuição do desmatamento na Amazônia brasileira: apoiar o manejo florestal familiar. Perspective (Cirad), n. 22. p. 1-4, 2013.

SIST, P. et al. Management of natural tropical forests in the pastand present and projections for the future. In: KATILA, P. et al. (Org.). Forests under pressure: local responses to global issues. Vienna: IUFRO World Series, 2014. p. 497-511.

SOUZA, A. P. O desenvolvimento socioambiental na Transamazônica: a trajetória de um discurso a muitas vozes. Dissertação (Mestrado em Agriculturas Familiares e Desenvolvimento Sustentável) Núcleo de Ciências Agrárias e Desenvolvimento Rural. Belém: Universidade Federal do Pará. 2006.

TORRES, M. Os assentamentos fantasmas e a metafísica da reforma agrária: análise da relação entre o Incra no oeste paraense, a extração ilegal de madeira e os números do II PNRA. GEOgraphia, v. 18, n. 37, p. 205-232, 2016.

TRECCANI, G. O título de posse e a legitimação de posse como formas de aquisição da propriedade. 2010. Disponível em: <http://www.pge.pa.gov.br/files/u13/ARTIGO\%206\%20-\%20DR.\%20GIROLAMO\%20 OKK>. Acesso em: 07 fev. 2018. 